\title{
HISTÓRIAS DE ESCOLARIZAÇÃO DE FUTUROS PROFESSORES: INVESTIMENTOS DA FAMÍLIA NA EDUCAÇÃO INFANTIL
}

\author{
STORIES OF SCHOOLING BY FUTURE TEACHERS: FAMILY'S INVESTMENTS \\ IN THE KINDERGARTEN
}

\section{HISTORIAS DE ESCOLARIZACIÓN DE FUTUROS PROFESORES: INVERSIONES FAMILIARES EM EDUCACIÓN INFANTIL}

\author{
Isabela VicenzoSgobbi Tulio \\ Graduação em Pedagogia - FCL/Unesp Araraquara \\ Mestrado em Educação Escolar - FCL/Unesp Araraquara \\ Doutorado em Educação - IB/Unesp Rio Claro \\ E-mail: isabelasgobbi@yahoo.com.br
}

\section{RESUMO}

O objetivo do presente artigo é mostrar os investimentos efetivados pelas famílias de futuros professores - alunos do curso de Pedagogia da Faculdade de Ciências e Letras/Campus de Araraquara/Unesp - durante o período da Educação Infantil de tais alunos. Nossas fontes são 272 histórias de escolarização produzidas, no âmbito da disciplina Didática II, nos anos 2005, 2009, 2013 e 2017 por alunos dos períodos diurno (133 alunos) e noturno (139 alunos) do referido curso. Para analisar nossos dados, utilizamos os procedimentos que advêm da técnica Análise de Conteúdo e trabalhamos com três categorias: Ações da Família, Discursos e Posturas da Família e Relação família-escola. Com relação ao tipo de instituição frequentada durante a Educação Infantil, há o predomínio das instituições públicas em ambos os períodos, sendo que as ações são a principal forma de investimento das famílias durante a Educação Infantil. Além disso, as mães são a figura mais citada pelos alunos como responsável pela efetivação das ações.

Palavras-chave: Participação da família. Alunos de Pedagogia. Educação Infantil.

\section{ABSTRACT}

The purposeofthisarticleisto show theinvestmentsrealizedbyfamiliesof future teachers (studentsofthePedagogyCourseat Faculdade de Ciências e Letras / Campus Araraquara/Unesp) duringthekindergartenperiodoftheovermentionedstudents. The researchsources are 272 stories ofschoolingproduced in 2005, 2009, 2013 and 2017 bystudentsofdiurnal (133 students) andnocturne (139 students) periods in the discipline ofDidactics II onthereferredCourse. The procedures of data analysis are basedonContentAnalysis' techniqueandweestablishedthreecategories: Family'sAction, Family's Speeches andPosturesand Family-Schoolrelationship. In relationtothesubjects' schooltrajectoryin thekindergarten, thereis a predominanceofpublicinstitutionsin bothperiods. The actions are themaininvestimentsoffamiliesand, in addition, mothers are themain figure citedbystudents as responsible for theactions.

Keywords: Family Participation. StudentsofPedagogy. ChildEducation.

$$
\text { RELEDUC | ISE | v. } 2 \text { | n. } 2 \text { | ago. } 2019
$$




\section{RESUMEN}

El objetivo del presente artículo es mostrar losinversiones que lasfamilias de futuros profesores - alumnosdel curso de Pedagogía de laFacultad de Ciencias y Letras / Campus Araraquara/ Unesp - efectuaron durante laeducación infantil de dichosalunos.Nuestrasfuentesson 272 historias de escolarizaciónproducidas, enelámbito de la disciplina Didáctica II, enlosaños2005, 2009, 2013 y 2017 por alumnos de los períodos diurno (133 alumnos) y nocturno (139 alumnos) de dicho curso. Para analizarnuestrosdatos, utilizamos losprocedimientos que vienen de la técnica Análisis de Contenido y determinamos trescategorías: Acciones familiares, Discursos y Posturas familiares y Relaciónfamiliaescuela. Sobre eltipo de instituición a la que asistió durante laeducación infantil, hayelpredominio de lasinstituciones públicas em ambos periodos. Lasaccionessonla principal forma de inversión de lasfamilias durante laeducación de laprimerainfancia. Además, las madres sonla figura más citada por losestudiantes como responsables de llevar a cabo lasacciones.

Palabras Clave: Participación de lafamilia. Alumnos de Pedagogía. Educación Infantil.

\section{INTRODUÇÃO}

O objeto do presente artigo $^{1}$ é descrever como a família de futuros professores alunos do Curso de Pedagogia da Faculdade de Ciências e Letras/Campus de Araraquara/Unesp - participou da trajetória escolar de seus filhos no período da Educação Infantil, explicitando quais investimentos foram realizados por essas famílias.

Nosso objetivo estabelece relação direta com as características de nossas fontes: relatos autobiográficos escritos pelos sujeitos, nos quais narram sua trajetória na educação básica. São 272 histórias de escolarização produzidas nos anos de 2005, 2009, 2013 e 2017, por alunos dos períodos diurno (133) e noturno (139) do referido curso, no âmbito da disciplina Didática II, oferecida no quinto semestre do curso. As fontes - denominadas Histórias de Escolarização - mostram uma faceta oculta da formação inicial de professores: o investimento de famílias na formação de seus filhos, neste caso, com o diferencial de se tratar de famílias de futuros professores.

Melo (2008) aponta potencialidades referentes ao uso das narrativas autobiográficas na formação docente:

\footnotetext{
${ }^{1}$ Os dados aqui apresentados fazem parte da pesquisa de doutorado intitulada 'Narrativas sobre a escolarização de futuros professores: investimentos da família’, defendida junto ao Programa de Pós-Graduação em Educação, do Instituto de Biociências/ Unesp Campus Rio Claro.
}

$$
\text { RELEDUC | ISE | v. } 2 \text { | n. } 2 \text { | ago. } 2019
$$


O uso das narrativas (auto)biográficas na formação docente possibilita evocar a historicidade e a subjetividade do indivíduo em formação, desvendando a experiência das trajetórias de escolarização, que fornece pistas sobre as práticas educativas que marcaram a sua vida [...] (MELO, 2008, p. 181).

Segundo Gadotti (2004), as narrativas autobiográficas estão se tornando cada vez mais importantes como matrizes pedagógicas de formação, ou seja, entendemos que dar voz a futuros professores, nesse caso falando sobre a participação familiar, pode ajudar a entender as características desse grupo, de modo a contribuir para o campo da formação de professores e para o próprio entendimento do contexto escolar.

Especificamente sobre as nossas fontes, tratam-se de documentos cujos conteúdos estão delimitados por um espaço finito de tempo, que compreende o período que vai desde a entrada na escola até o ingresso na universidade e o conteúdo das narrativas são as experiências vividas nesse período. No que diz respeito ao procedimento metodológico da produção de nossas fontes, a inspiração da forma da narrativa veio de Elias Canetti (1987), especificamente, do livro A Língua absolvida. Tal obra é a referência fundamental para a produção das histórias, funcionando como inspiração e estímulo de narrativa, ou seja, sugestão de forma e conteúdo.

Partimos de uma abordagem analítico-descritiva e para análise das fontes utilizamos os procedimentos que vem da técnica Análise de Conteúdo (BARDIN, 1977), que nos permite trabalhar com aquilo que foi explicitamente registrado pelos sujeitos em seus relatos escritos. As categorias que estabelecemos surgiram a partir das leituras das fontes, tendo como perguntas norteadoras: Como a família de futuros professores investiu e participou na educação básica? Quais investimentos foram realizados pelas famílias? O que os relatos dos alunos revelam sobre a participação da família? Desse modo chegamos a três categorias: ações da família, discursos e posturas da família e relação família/escola.

\section{OS INVESTIMENTOS DAS FAMÍLIAS DE FUTUROS PROFESSORES NA EDUCAÇÃO INFANTIL: O QUE DIZEM NOSSAS FONTES}

Primeiramente, faz-se importante destacar que em nossas fontes, a quantidade de mulheres é muito superior à de homens, alcançando 95,8\%, enquanto os homens correspondem a 4,1\%. A superioridade das mulheres acontece nos dois períodos (diurno e

$$
\text { RELEDUC | ISE | v. } 2 \text { | n. } 2 \text { | ago. } 2019
$$


noturno) nos quais o curso de Pedagogia é oferecido na FCL. A esse respeito, sabemos que a questão da feminização da docência, principalmente nas fases iniciais da educação básica, que é justamente a habilitação fornecida pelo referido curso, é histórica e ligada a dois fatores principais: a docência como única oportunidade das mulheres prolongarem os estudos e a ideia difundida dos dons femininos para trabalhar com as crianças.

No que se refere ao tipo de instituição frequentada na Educação Infantil, temos os seguintes dados:

Tabela 1 - Tipos de instituição frequentadas na Educação Infantil - diurno.

\begin{tabular}{cccccc}
\hline $\begin{array}{c}\text { Educação } \\
\text { Infantil }\end{array}$ & $\begin{array}{c}\text { Não } \\
\text { cursou }\end{array}$ & Pública & Particular & Mista & Total \\
\hline $\mathbf{2 0 0 5}$ - diurno & 2 & 16 & 14 & 5 & 37 \\
$\mathbf{2 0 0 9}$ - diurno & 1 & 15 & 8 & 1 & 25 \\
$\mathbf{2 0 1 3}$ - diurno & 2 & 19 & 13 & 3 & 37 \\
$\mathbf{2 0 1 7}$ - diurno & 1 & 19 & 5 & 9 & 34 \\
\hline Total & 6 & 69 & 40 & 18 & 133 \\
\hline & & & \multicolumn{2}{c}{ Fonte: elaboração própria. }
\end{tabular}

Tabela 2 - Tipos de instituição frequentadas na Educação Infantil - noturno.

\begin{tabular}{cccccc}
\hline $\begin{array}{c}\text { Educação } \\
\text { Infantil }\end{array}$ & $\begin{array}{c}\text { Não } \\
\text { cursou }\end{array}$ & Pública & Particular & Mista & Total \\
\hline $\mathbf{2 0 0 5}$ - noturno & 8 & 21 & 4 & 2 & 35 \\
$\mathbf{2 0 0 9}$ - noturno & 2 & 16 & 3 & 5 & 26 \\
$\mathbf{2 0 1 3}$ - noturno & 5 & 24 & 4 & 5 & 38 \\
$\mathbf{2 0 1 7}$ - noturno & 2 & 31 & 3 & 4 & 40 \\
\hline Total & 17 & 92 & 14 & 16 & 139 \\
\hline & & & & \multicolumn{2}{c}{ Fonte: elaboração própria. }
\end{tabular}

Considerando-se o grupo de alunos do período diurno (133), temos o predomínio da escola pública (69 alunos), seguido da particular (40 alunos) e da mista ${ }^{2}$ (18). Nesse grupo, há 6 alunos que não frequentaram a educação infantil, cuja escolarização iniciou-se diretamente na então $1^{\mathrm{a}}$ série. Vale dizer que a educação infantil só foi reconhecida como primeira etapa da educação básica brasileira em 1996, com a Lei de Diretrizes e Bases (Lei federal nº 9.394, de 20 de dezembro de 1996), que tornou obrigatória a escolarização das crianças a partir dos quatro anos de idade. Entretanto, apesar da não obrigatoriedade da escolarização, a maior parte dos sujeitos do período diurno frequentou a Educação Infantil, o que já pode nos mostrar a valorização do ambiente escolar por essas famílias.

\footnotetext{
${ }^{2}$ Trajetória mista refere-se a alunos que passaram por instituições públicas e particulares, seja no mesmo ano ou em anos diferentes. 
Os dados levantados junto aos alunos do período noturno (139) mostram que a maioria cursou a educação infantil também em escolas públicas, alcançando 66,2\%. Na sequência temos: $12,2 \%$ não cursaram a educação infantil, 11,5\% cursaram-na em instituições públicas e privadas e por fim, 10,1\% cursaram-na em instituições particulares. Enquanto no grupo diurno apenas 6 sujeitos não passaram pela educação infantil, no grupo noturno temos quase o triplo dessa quantidade; no primeiro grupo, as instituições particulares apareceram em segundo lugar e, aqui, em quarto. Portanto, já na primeira etapa da escolarização, os dados mostramnos que alunos dos períodos diurno e noturno têm trajetórias diferenciadas em seu percurso escolar, embora em ambos os grupos a instituição pública predomine na etapa em questão. Teriam esses percursos diferenciados, já na Educação Infantil, relação com a escolaridade dos pais ou com o capital cultural familiar?

Para tentar responder, vale aqui destacar os dados sistematizados por Spazziani, Oliveira e Pinho (2016) com relação ao nível de instrução dos pais dos alunos ingressantes no curso de Pedagogia da FCL no período de 2006 a 2015: 32,4\% dos pais do período diurno tem o Ensino Médio Completo enquanto $32 \%$ dos pais do período noturno tem o Ensino Fundamental Incompleto, ou seja, o perfil de escolarização dos pais dos dois períodos é diferente.Com relação às mães, em ambos os períodos, predominam mães que possuem o Ensino Médio Completo (34,8\% - diurno e 29,5\% - noturno). Sabe-se que existe uma relação de interdependência entre as condições sociais das famílias e as formas de relação estabelecidas com a escola:

Outra consideração que cabe aqui assinalar é a interdependência entre as condições sociais de origem das famílias e as formas de relação que estas estabelecem com a escola. As famílias, assim como a escola, não podem ser consideradas de forma abstrata, dissociadas de suas condições históricas e socioculturais. Como já tem sido apontado por vários pesquisadores, variam consideravelmente as formas de interação que as camadas médias e as camadas populares estabelecem com os professores e - de modo geral-com a instituição onde estudam seus filhos, ou ainda, as práticas que adotam para favorecer a escolarização dos mesmos. (ROMANELLI; NOGUEIRA; ZAGO, 2011, p. 10 e 11).

Romanelli, Nogueira e Zago (2011) falam em comportamentos operantes dos pais sobre o percurso escolar, o que abrange desde a ajuda nos deveres de casa à organização dos tempos e espaços domésticos e também os dispêndios financeiros, entre outros. Já Portes (2011) trabalhou com a noção de trabalho escolar e nos explica tal conceito:

$$
\text { RELEDUC | ISE | v. } 2 \text { | n. } 2 \text { | ago. } 2019
$$


Entendemos aqui por trabalho escolar todas aquelas ações - ocasionais ou precariamente organizadas - empreendidas pela família no sentido de assegurar a entrada e permanência do filho no interior do sistema escolar, de modo a influenciar a trajetória escolar do mesmo, possibilitando a ele alcançar os níveis mais altos de escolaridade, como, por exemplo, ter acesso ao curso superior. (PORTES, 2011, p. 63).

No que se refere as nossas categorias para explicitar os investimentos das famílias de futuros professores na Educação Infantil, temos primeiramente a categoria 'Ações da família' englobando a participação da família por meio de ações efetivas, como compra de livros e materiais diversos, contação de histórias pelos pais, ajudas em tarefas escolares, a participação em atividades e reuniões, dentre outras. Intitulamos nossa próxima categoria analítica como 'Discursos e posturas da família', considerando que fazem parte desta categoria todos os discursos (entendidos como mensagens orais, atos verbais, ensinamentos familiares) e as posturas (entendidas como maneira de pensar, ponto de vista, opinião ou posicionamento) da família durante a trajetória escolar.

Por fim, na categoria 'Relação família-escola' encontram-se os episódios que apresentam justamente a relação da família com a escola, sendo que a iniciativa pode vir de ambas as partes, família ou escola, e cujo objetivo é sempre resolver algum conflito, problema ou situação envolvendo o aluno.

Quantitativamente, no período da educação infantil, localizamos em nossas fontes 48 ações (32 no período noturno e 16 no período diurno), sendo as famílias do período noturno responsáveis pelo dobro de ações do que o período diurno.

Os alunos do período diurno relataram ações efetivadas em casa como fazer as tarefas junto, ensinar músicas, alfabetizar, presentear com livros e disponibilizar materiais de escrita. Tais ações funcionam como um complemento daquilo que era realizado no ambiente escolar, reforçando ou diversificando as aprendizagens:

Minha mãe teve papel efetivo nesse período, lembro-me claramente que toda tarde sentava-se pacientemente ao meu lado para me ajudar com as tarefas, buscava em seus livros novas tarefas e acrescentava ainda atividades que se recordava de seu tempo de aluna. Isso acelerou positivamente meu processo de alfabetização [...] Lembro-me que onde ela [a mãe] estivesse eu corria para junto dela com lápis e papel em mãos, na sala, cozinha, varanda e até durante meu banho as lições aconteciam, ela me dizia uma palavra e pedia para que soletrasse [...] (Sujeito 28, 2017, diurno)

$$
\text { RELEDUC | ISE | v. } 2 \text { | n. } 2 \text { | ago. } 2019
$$


Tenho lembrança deste período quando ganhei de meu pai um pequeno baú com livros de contos de fada clássicos, em pouco tempo havia lido e relido todos os contos e me sentia feliz e realizada por conseguir fazê-lo. (Sujeito 28,2017 , diurno)

Dois sujeitos do período diurno relataram a ação dos pais de investir em escola particular no período da Educação Infantil como forma de garantir uma formação de qualidade para os filhos:

Foi então que ela me matriculou em uma escola de educação infantil particular [...] o transporte era realizado de van e mesmo que as mensalidades de ambos fossem caras, meus pais faziam o possível e impossível para que eu tivesse uma educação de qualidade. (Sujeito 24, 2017, diurno)

Por fim, os sujeitos do período diurno relataram ainda ações de participação dos pais em atividades oferecidas pela escola, em reuniões e o envolvimento com o cotidiano escolar por meio de perguntas sobre atividades realizadas na escola:

Esta instituição, na qual eu passei meu primeiro ano significativo dentro de uma escola, possibilitava um grande envolvimento dos pais nas atividades escolares. Lembro-me de várias vezes em que meus pais foram participar de algo que era realizado no colégio. (Sujeito 3, 2009, diurno)

[...] minha mãe também sempre foi daquelas que não faltava em nenhuma reunião, e conversava muito com as professoras, dessa forma sempre foi muito querida, por se mostrar sempre tão preocupada com nosso rendimento e comportamento [...] (Sujeito 26, 2013, diurno)

No período noturno, encontramos ações da família para resolver problemas específicos, por exemplo, retirar da escola por causa do choro excessivo. Importante apontar que os alunos do período diurno não relataram situações de problema que exigiram ações da família no período da Educação Infantil:

Minha história de escolarização começou no ano de 1988, lembro que minha mãe matriculou-me no jardim de infância, que funcionava em um clube da prefeitura [...] Mas lembro que chorava muito não queria ficar sozinha, queria que minha mãe ficasse comigo, por isso durante uma semana ela me levava e permanecia comigo o tempo todo na aula para tentar fazer me acostumar com o novo ambiente, mas isso não ocorreu, não aceitava ficar sem minha mãe, então ela resolveu tirar-me do jardim de infância e esperar o próximo ano para matricular-me na pré-escola. (Sujeito 13, 2005, noturno). 47

RELEDUC | ISE | v. 2 | n. 2 | ago. 2019 
Outro sujeito do período noturno também cita uma situação de problema no período da Educação Infantil, a qual leva a mãe a mudar a filha de escola:

A professora lia o livro cada dia com uma criança no colo. Menos eu. Eu não entendia o porquê. $O$ sentimento que eu tinha em mim era de nãopertencimento. Sentia que a escola não era acolhedora. E como que eu queria conquistar essa professora, mas não sabia como. Minha mãe percebeu que havia alguma coisa errada, mas eu não contava. [...] No entanto assim que terminou esse ano, e minha mãe percebeu que eu não gostava de ir à escola, ela tomou uma atitude, como abriu mais vagas numa escola mais próxima de casa, me matriculou nesta. (Sujeito 29, 2017, noturno)

Ademais, os alunos do período noturno citaram ações efetivadas em casa como ensinar a ler e escrever, contar histórias, passar atividades e tarefas, fazer tarefa junto, comprar livros, comprar materiais e encapar livros e cadernos, além de levar à biblioteca. As ações de participar das atividades da escola, de reuniões, apreciar os trabalhos e elogiar, preocupação com o cotidiano escolar também foram citadas pelos alunos do período noturno:

Nessa idade eu gostava muito de ver livrinhos de histórias, minha mãe sempre me contava historinhas, e gostava também de livros de colorir, sempre que ia ao mercado ou a feira com a minha mãe ela me comprava um, quando não era ela que ia e sim meu pai ele também me trazia livrinhos de pintura e história para minha mãe ler para mim, ela fazia isso comigo e com meus três irmãos. (Sujeito 3, 2013, noturno)

As mais frequentes atividades eram as comemorações, como por exemplo: páscoa, festa junina, dia das crianças, dia das mães, dia dos pais, festa de encerramento do ano com temática natalina, entre outros eventos. Minha mãe estava presente em todos, pois achava importante acompanhar de perto a atuação escolar das filhas. Guardo na memória a preocupação, da minha mãe em saber sobre meu cotidiano escolar, todos os dias depois da escola me perguntava o que tinha feito e aprendido na escola. Essa lembrança ficou marcada pelas conversas que tínhamos no caminho de volta pra casa, que era longo [...] (Sujeito 6, 2013, noturno)

Observamos que nos dois períodos (diurno e noturno) mantêm-se as ações que valorizam a leitura e os conhecimentos ligados à escrita e leitura, além de serem as mães a figura mais citada enquanto responsáveis pelas ações na Educação Infantil por alunos de ambos os períodos.

48

RELEDUC | ISE | v. 2 | n. 2 | ago. 2019 
A categoria 'Discursos e Posturas da família' ficou composta por 14 excertos (9 diurno e 5 - noturno). A diferença quantitativa entre os dois períodos é pequena, porém em proporção contrária ao que mostraram as ações, quando o período noturno, na Educação Infantil, ficou à frente do diurno. Os discursos e posturas da família na Educação Infantil, relatados pelos alunos do período diurno, revelam a importância atribuída à escola, a valorização do ambiente escolar e o apoio e os incentivos recebidos em casa por parte da família (principalmente na figura dos pais, porém, em um excerto, aparece a figura dos avós):

Quando o sinal bateu e eu vi a minha mãe na porta da sala, minhas lágrimas pararam na hora e eu voltei a ser feliz. Chegando em casa, falei que eu não queria voltar pra escola, mas ela me explicou que era preciso, para eu aprender muitas coisas. (Sujeito 1, 2009, diurno).

Minha família sempre me preparou para esse dia tão especial, principalmente a minha mãe, que me contava as suas histórias escolares e enfatizava sempre que a escola seria um lugar onde eu iria aprender muitas coisas, como ler, escrever, além de fazer muitos amigos [...]. (Sujeito 17, 2009, diurno).

Ela [mãe] conta que me deixou na escola com muito aperto no coração e que eu apesar de ansiosa, por querer ir pra escola, aparentava apreensiva e com medo, por um instante quis voltar pra casa, mas então ela me levou até a sala e disse que ali eu iria conhecer novos amigos e aprender coisas novas, com a professora. Ela me deixou e foi embora, conta que chorou quando chegou em casa, mas entendia que seria bom para mim. (Sujeito 34, 2013, diurno).

No que se refere ao período noturno, são apenas 5 excertos de discursos/posturas da família, enquanto que as ações na Educação Infantil chegaram a 32, ou seja, no primeiro nível escolar frequentado pelos alunos, as famílias do período noturno investem mais por meio de ações do que por meio de discursos. Isso também aconteceu com as famílias do período diurno, embora sem diferença tão extrema de quantidade. Em quatro dos cinco relatos do período noturno os sujeitos destacaram o discurso de valorização da escola e das aprendizagens proporcionadas nela e por ela, sendo que em dois os familiares contam aos alunos sobre sua própria escolarização, como um incentivo para fazer diferente:

[...] minha mãe me encheu de expectativa, como ela não pode continuar os estudos, queria me mostrar que a educação transforma, a partir do momento em que eu tivesse acesso a ela já me tornaria uma pessoa diferente, através dela me colocaria em lugares diferentes, não para me sentir melhor que os outros, mas para ser "alguém", me tornar alguém melhor, pela educação eu iria conseguir coisas que devido à falta de estudos da minha mãe, ela não conseguiu. (Sujeito 14, 2017, noturno)

$$
\text { RELEDUC | ISE | v. } 2 \text { | n. } 2 \text { | ago. } 2019
$$


Lembro-me que não fui daquelas crianças que dão trabalho para os pais e que choram por terem que ir à escola, talvez porque minha mãe teve uma conversa comigo acabou indo tudo bem. Lembro-me que ela disse que na escola a professora era como se fosse minha mãe... acho que funcionou porque eu nunca dei trabalho. (Sujeito 7, 2009, noturno)

No início, antes de ingressar na escola, meus pais me diziam que "lá" era um lugar muito legal, onde eu iria aprender muitas coisas, fazer muitos amigos e teria diversas coisas legais para fazer. (Sujeito 13, 2009, noturno)

No outro dia, lá estávamos de novo, me lembro da minha avó dizer "[...] é tão gostoso ir à escola. Se eu pudesse, naquele tempo, eu não teria parado. Só parei porque eu precisei ir trabalhar." Eu realmente, não entendi, naquele momento o porquê minha avó me parecer tão sincera. (Sujeito 29, 2017, noturno)

De maneira geral, observou-se em ambos os períodos a importância atribuída à escola e consequente valorização de tal ambiente e das aprendizagens proporcionadas nela e por ela, além do apoio e os incentivos recebidos em casa por parte da família, principalmente na figura dos pais.

Por fim, na categoria 'Relação Família-escola' temos apenas 3 excertos do período diurno e 8 do período noturno. Nos dois trechos a seguir, há exemplos da relação famíliaescola na Educação Infantil e ambos mostram a relação da mãe com a diretora:

Recordo-me de minha mãe discutindo com a diretora na sala desta por que ela havia pedido uma lista imensa de material no começo do ano, como roupa para ballet e judô e não as utilizava por que raramente havia esse tipo de atividade na instituição. (Sujeito 9, 2005, diurno).

No ano seguinte eu iria para o Pré II, porém minha mãe conversou com a diretora da escola e pediu para que me colocassem já no Pré III. Isso era porque a professora que dava aula nessa última série iria se aposentar e minha mãe a considerava ótima e não gostaria que eu tivesse outra a não ser ela. Após conversar, ficou decidido que eu iria "pular" uma série e então comecei no Pré III. (Sujeito 17, 2009, noturno).

Já nos trechos a seguir pode-se visualizar a relação que parte da escola e chega até a família; os quatro exemplos encontrados desse tipo de relação na Educação Infantil foram extraídos do período noturno, ou seja, não há exemplos de relação que parte da escola para a família na Educação Infantil relatados por alunos do período diurno. Nos dois primeiros 
exemplos, os pais recebem propostas/orientações para adiantar a escolarização dos filhos e os dois últimos exemplificam a relação da professora com os pais:

Quando estava na turma de cinco anos, a direção chamou a minha mãe para conversar, disse que eu tinha um ótimo desempenho e gostaria da autorização dela para me encaminhar para primeira série ao invés de ir para a pré-escola. A minha mãe não concordou, pois além de me achar muito nova, ficou com medo de que eu pulasse alguma fase importante de meu desenvolvimento. (Sujeito 21, 2009, noturno).

Completei seis anos em setembro de 1994 nessa etapa, e minha mãe comentou que ao conversar com a professora Ângela em uma reunião, a mesma disse que eu não deveria perder tempo em fazer o jardim II, e sim que minha mãe me matriculasse direto na primeira série no ano seguinte, pois eu era uma menina muito esperta e inteligente e que fazer o jardim II iria só me atrasar. (Sujeito 2, 2017, noturno)

[...] tenho algumas recordações da mesma elogiando os seus alunos para os pais, ela convidava os pais para irem até a creche e mostrava nossos trabalhinhos com muito orgulho para eles, que, consequentemente, também ficavam bastante orgulhosos. (Sujeito 20, 2017, noturno).

[...] quando a professora descobriu que eu desenhava muito bem, e chamou minha mãe para contar tal descoberta. E quando minha mãe viu meus desenhos, percebeu que eram muito parecidos com os do meu pai, e compreendi que de certo modo herdei o dom de desenhar dele. (Sujeito 1, 2009, noturno)

Considerando-se as três categorias, temos, por período, quantitativamente os seguintes investimentos:

- Período diurno: Ações (16); Discursos e Posturas (9); Relação família-escola (3).

- Período noturno: Ações (32); Relação família-escola (8);Discursos e posturas (5).

Nos dois grupos de sujeitos (diurno e noturno), são as mães a figura familiar mais presente, durante a Educação Infantil, nas três categorias com as quais trabalhamos; são elas que mais estudam com os filhos, ensinam em casa ou fazem as tarefas junto; vão até a escola em reuniões e eventos, relacionam-se com os professores para tentar resolver conflitos ou problemas; compram materiais e brinquedos, incentivam a leitura e valorizam a escola.

\section{CONSIDERAÇÕES FINAIS}

Bourdieu (2012, p. 42) defende que: "Mais do que os diplomas obtidos pelo pai, mais mesmo do que o tipo de escolaridade que ele seguiu, é o nível cultural global do grupo 51

$$
\text { RELEDUC | ISE | v. } 2 \text { | n. } 2 \text { | ago. } 2019
$$


familiar que mantém a relação mais estreita com o êxito escolar da criança.”. O autor afirma ainda que: "[...] a ação do meio familiar sobre o êxito escolar é quase exclusivamente cultural" (2012, p. 42). Os dois grupos de nossos sujeitos, pertencentes a períodos diferentes no curso de Pedagogia, apresentam perfis de investimento semelhante durante o período da Educação Infantil, com a predominância de ações familiares. Vale dizer que os nossos dados apontaram mais investimentos das famílias dos futuros professores do período noturno e lembrando que também observou-se diferenças nos níveis de escolaridade dos pais e mães dos alunos do período diurno e noturno.

Comparar as trajetórias dos grupos permitiu compreender como as práticas sociais, econômicas e a herança cultural advinda da família podem interferir nas trajetórias escolares de estudantes e consequentemente na escolha do curso superior. Tais práticas deixam marcas nos sujeitos, em suas identidades pessoais e profissionais. Nos dois grupos foi possível observar a participação ativa e positiva da família na vida escolar dos alunos, desde o período da Educação Infantil. Importante também destacar que os dados que encontramos em nossas fontes ajudam a desconstruir o mito da omissão parental (Lahire, 1997), normalmente produzido pelos professores que afirmam que os pais não se incomodam com os filhos.

Consideramos que conhecer as trajetórias dos estudantes de Pedagogia, no que se refere à participação da família, pode oferecer dados relevantes para pensarmos nas representações que tais alunos - futuros professores - foram construindo ao longo de sua vivência escolar. Os dados apontados podem também fornecer pistas para a escola básica melhorar a relação com as famílias, além de apontar para a própria formação inicial, no sentido de abrir espaço para as reflexões e (des)construções necessárias. A participação da família na escola pode ser um aspecto potencializador da qualidade da aprendizagem escolar.

\section{REFERÊNCIAS BIBLIOGRÁFICAS}

BARDIN, Laurence. Análise de Conteúdo. Trad. Luís Antero Reto e Augusto Pinheiro. Lisboa: Edições 70, 1977.

BOURDIEU, Pierre. O capital social - notas provisórias. In: NOGUEIRA, Maria Alice.; CATANI, Afrânio. (org.). Escritos de Educação. 13. ed. Petrópolis, RJ: Vozes, 2012, p. 6569.

Os três estados do capital cultural. In: NOGUEIRA, Maria Alice.; CATANI, Afrânio.

(org.). Escritos de Educação. 13. ed. Petrópolis, RJ: Vozes, 2012, p. 71-79.

$$
\text { RELEDUC | ISE | v. } 2 \text { | n. } 2 \text { | ago. } 2019
$$


CANETTI, Elias. A língua absolvida: história de uma juventude. Trad. Kurt Jahn. São Paulo: Companhia das Letras, 1987.

GADOTTI, Moacir. Os mestres de Rousseau. São Paulo: Cortez, 2004.

MELO, Maria José Medeiros Dantas de. Olhares sobre a formação do professor de Matemática. Imagem da profissão e escrita de si.2008. 322 f. Tese (Doutorado em Educação) - Universidade Federal do Rio Grande do Norte, Natal, 2008.

PORTES,Écio Antônio. O trabalho escolar das famílias populares. In: NOGUEIRA, Maria Alice; ROMANELLI, Geraldo; ZAGO, Nadir (orgs.). Família e escola: trajetórias de escolarização em camadas médias e populares. 6. ed. Petrópolis, RJ: Vozes, 2011, p. 61-80.

ROMANELLI, Geraldo; NOGUEIRA, Maria Alice; ZAGO, Nadir. Introdução. In: NOGUEIRA, Maria Alice; ROMANELLI, Geraldo; ZAGO, Nadir (orgs.). Família e escola: trajetórias de escolarização em camadas médias e populares. 6. ed. Petrópolis, RJ: Vozes, 2011, p. $9-15$.

SPAZZIANI, Maria de Lourdes; OLIVEIRA, José Brás Barreto de; PINHO, Sheila Zambello de. Perfil socioeconômico e sociocultural dos ingressantes nos cursos de graduação: 2006-2015: ciências humanas. São Paulo: Universidade Estadual Paulista, Pró-Reitoria de Graduação: Vunesp, 2016. 472p. 